\section{Operation Rainbow Canada - Unexpected middle ear findings in a small group of Philippine teenagers and young adults with unrepaired cleft palates}

\section{Dear Sir,}

During a trip to the Philippines with Operation Rainbow Canada, we encountered some unusual findings, as follows:

From February 9 to 23, 2006, a team of doctors, nurses and clerical staff from Operation Rainbow Canada worked in Carbanatuan City in Neuva Ecija, Luzon, in the Philippines, to see and treat indigent children with cleft lips and palates.

The team (see Appendix), consisting of two pediatricians, four plastic surgeons, three anesthetists, one orthodontist and one pediatric otolaryngologist, examined all patients with cleft lip or palate problems.

\section{METHOD}

All patients or parents were mainly concerned about their appearance and their speech. Many of the older children had dropped out of school because of teasing, and were found to be rather withdrawn and shy children and adults. They were also poor.

During the ear, nose and throat examination, questions were asked such as:

1. "Do you think you/your child's hearing is good?" (90\% answered "yes").

2. "Have/has you/your child had any earaches or ear infections ever?" (Almost all answered "no").

Pneumatic otoscopy was performed and the impedance of each ear was measured using a Welch Allyn MicroTymp 2 hand-held device. Middle ear effusions were diagnosed if the drum looked opaque, retracted and immobile, also taking into account its colour and if the impedance showed type B or C.

\section{RESULTS}

Local doctors had identified 52 cleft palate patients before our visit and once the news spread, it resulted in us seeing 141 patients, although 62 of these patients did not have a cleft lip or palate. Of the 79 patients with cleft lip and/or palate problems, 64 had surgery (an additional three patients had surgery for burn contractures).

We found 11 children/adults with unilateral incomplete cleft lips (normal palates), 41 with complete unilateral cleft lip and palate, and 21 with bilateral cleft lip and palate. Six patients had had a previous repair of either the

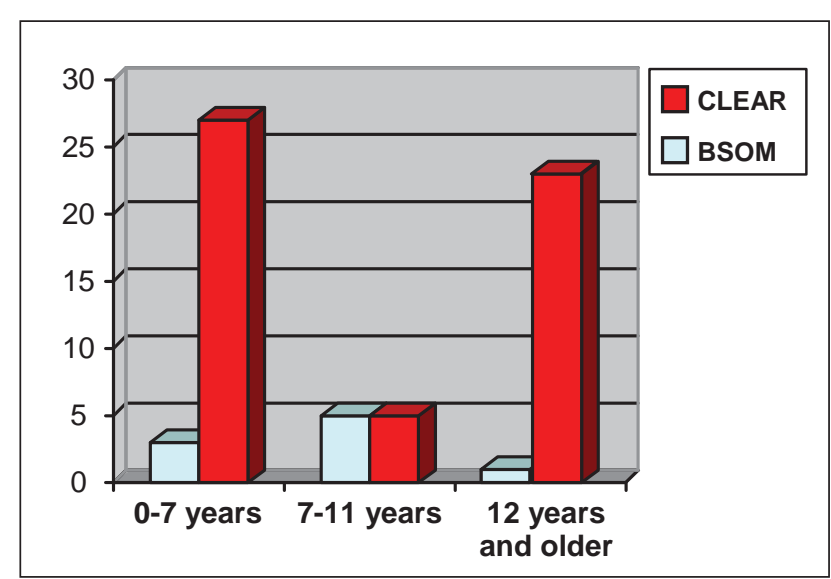

Figure 1) Number of patients with unrepaired cleft palates who had clear middle ears or bilateral serous otitis media (BSOM) in three different age groups - 0 to 7 years, 7 to 11 years and 12 years and older. The presence of BSOM was determined by pneumatic otoscopy and impedance tympanometry. (The number of patients $[n=64]$ is, by coincidence, the same number of patients that had surgery. However, the 64 patients who had surgery included some incomplete cleft lips [normal palates]. The figure includes all patients with unrepaired cleft palates, some of whom did not receive surgery.)

lip alone or the lip and palate. The ages ranged from three months to 35 years.

The younger children had problems with their ears, even though most of the parents voiced no complaints about them. Bilateral middle ear effusions would normally give a patient a mild or moderate hearing loss (20 dB to $60 \mathrm{~dB}$ loss), which usually would be significant, affecting speech development in the younger age group and definite hearing problems in the older, school-aged children. Those children whose parents did have complaints about their children's ears usually had perforations that would discharge from time to time (and thus be noticed).

Twenty-four patients older than 12 years of age were seen. They all had unrepaired cleft palates. Expectations were that these patients would have severe middle ear problems, but, on the contrary, they almost universally had clear ears with reasonably normal tympanic membranes. Impedance was also normal (Figure 1). The teenagers were asked to perform the Valsalva manoeuvre (increase the pressure in the nasopharynx by holding the nose while actively exhaling) and then impedance was repeated. These usually showed positive pressure peaks and the tympanic membrane was seen to move when observed during a Valsalva manoeuvre.

Dr Paul Helpard, the orthodontist, noted that only two of all the patients he saw had healthy teeth. Many 
young children and teenagers had caries in every tooth, but almost universally had no complaints about pain.

\section{Procedure}

Myringotomies were performed on 53 ears (27 patients) using an otoscope with an operating head, and Armstrong tubes were placed. Posteoperatively, each patient was given a bottle of antibiotic ear drops and a pamphlet about tube care.

\section{DISCUSSION}

These were indigent children and adults who had very few complaints about either their ears or their carious teeth, both of which would have been expected to cause discomfort. The stress of poverty overrides physical pain. (Scientific American: December 2005 [1]; "Sick of Poverty" explains why this might be).

Bluestone and Klein (2) have established that children's eustachian tubes are always closed and are actively opened by the tensor veli palatini muscle. The levator palatini stabilizes the medial crus of the eustachian tube. The fact that many teenagers had normally ventilated middle ears must mean that their eustachian tubes can be opened by the presence of a pressure differential, ie, when the pressure in the pharynx (nasopharynx) is high enough, the eustachian tube opens and the middle ear air is replenished. Several teenagers and young adults with unrepaired cleft palates were asked to perform the Valsalva manoeuvre and then their ears had impedance testing. All patients showed a peak in the positive range, indicating that air had entered the middle ear.

Gunther et al (3) and Guneren et al (4) suggested that placement of tubes in the younger children prevented middle ear problems later.

It would seem that neither Bluestone, Guneren nor Gunther might be entirely correct based on the population we saw.

\section{CONCLUSIONS}

Many teenagers and older patients with unrepaired palates were able to ventilate their middle ears without their tensor veli palatini muscles functioning. They could ventilate their ears by doing a Valsalva manoeuvre.

It was also noted that neither the parents nor the children had detected a mild or moderate hearing loss and had no complaints about ear infections or ear aches.

Young children, afflicted teenagers or young adults did not complain about toothache in spite of severe caries.
It would be interesting to compare these findings with thos of unrepaired cleft lip and palate patients from other groups and other countries.

\section{APPENDIX}

\section{THE OPERATION RAINBOW CANADA TEAM}

The team consisted of two pediatricians; Dr J Druker MBChB DCH FRCPC, a Clinical Assistant Professor, and Dr Shawn George MD, Chief of Pediatric Residents at BC Children's Hospital; four plastic surgeons, Dr Don Fitzpatrick MD FRCSC, a Clinical Associate Professor, Dr Louise Laberge MD FRCSC, a Clinical Associate Professor, Dr Corstiaan Breugem MD, a Fellow in Plastic Surgery at BC Children's Hospital, and Dr Rebecca Morley MD, a second year Plastic Surgery Resident; three anesthetists, Dr Clayton Reichert MD FRCPC (the Team Leader), Dr Mahesh Arora MD FRCP, Professor in Anesthesia, Dr Nigel Baker MB ChB, a Fellow in Pediatric Anesthesia at BC Children's Hospital; an orthodontist, Dr Paul Helpard; and a pediatric otolaryngologist, Dr Keith Riding MB BS FRCSC, Clinical Professor, who screened all the children, with the help of interpreters, Robert Pinlac, Segundo Padolina (also Site Coordinator), Claire Padolina RN, Shirley Maas RN (also Mission Coordinator), Ana Pesch RN and Juliet Takahashi RN. After screening, suitably healthy candidates were then operated on with the help of the operating room nurses Ingrid Aucoin RN, (Operating Room Coordinator), Annette Gardin RN, Cindy Moreno RN and Rema Nair RN. The recovery room nurses were Caroline Kolhberg RN and Sue Taylor RN. Sandi Cleary collected and collated all the data.

Keith H Riding MB BS FRCSC British Columbia Children's Hospital Vancouver, British Columbia

\section{REFERENCES}

1. Sapolsky R. Sick of Poverty. Scientific American, December 2005.

2. Bluestone CD, Klein JO. Otitis media, atelectasis and eustachian tube dysfunction. In: Bluestone CD, Stool S, eds. Pediatric Otolaryngology, 2nd edn. Philadelphia: WB Saunders, 1990:320-483.

3. Gunther E, Wisser JR, Cohen MA, Brown AS. Palatoplasty: Furlow's double reversing Z-plasty versus intravelar veloplasty. Cleft Palate Craniofac J 1998;35:546-9.

4. Guneren E, Ozsoy Z, Ulay M, Eryilmaz E, Ozkul H, Geary PM. A comparison of the effects of Veau-Wardill-Kilner palatoplasty and furlow double-opposing Z-plasty operations on eustachian tube function. Cleft Palate Craniofac J 2000;37:266-70. 